\title{
"Robust Exploration and Commercial Missions to the Moon Using LANTR Propulsion and In-Situ Propellants Derived From Lunar Polar Ice (LPI) Deposits"
}

\author{
AIAA-2017-5272 \\ EXPL-04: Advance Propulsion and Power Systems \\ Stanley K. Borowski, Stephen W. Ryan, Laura M. Burke (NASA/GRC) \\ David R. McCurdy, James E. Fittje (Vantage Partners, LLC at GRC) \\ Claude R. Joyner (Aerojet Rocketdyne) \\ 216-977-7091, Stanley.K.Borowski@nasa.gov
}

presented at the

2017 AIAA Space Forum and Exposition - Space 2017

Hyatt Regency Orlando

Orlando, Florida

Wednesday, September 13, 2017 


\section{Background Information and Presentation Overview}

- NASA's current focus is on the "Journey to Mars" sometime around the mid-to-late 2030's. However, it is also supporting the development of commercial cargo and crew delivery to the ISS (e.g., Space $X$, Orbital ATK, SNC, Boeing) where inflatable habitation technology (e.g., Bigelow Aerospace's BEAM) is currently being tested

- Significant private sector interest in commercial lunar activities has also been expressed by Bigelow Aerospace, Blue Origin, Golden Spike Company, Shackleton Energy Company (SEC), and most recently by United Launch Alliance (ULA) in their "Cislunar-1000" plan

- Lunar-derived propellant (LDP) production offers significant mission leverage and are central themes of both SEC's and ULA's plans for commercial lunar development

- An efficient, proven propulsion technology with reuse capability - like NTP - offers the potential for affordable "access through space" essential to realizing commercial lunar missions

- Question: How can high performance NTP and the leverage potential of LDP best be exploited? Answer: " $L \mathrm{O}_{2}$-Augmented" NTR (LANTR) - $\mathrm{LH}_{2}$-cooled NTR with "O $\mathrm{O}_{2}$-afterburner" nozzle combines $N T R$ and supersonic combustion ramjet engine technologies allowing "bipropellant" engine operation

- This presentation examines the performance potential of an "evolutionary" lunar transportation system (LTS) architecture using NTR initially, then transitioning to LANTR as LDP (e.g., specifically LLO Lnd $\mathrm{LLH}_{2}$ derived from LPI) become available at propellant depots in lunar equatorial and polar orbits

- Cargo delivery, crewed landing, space-based crewed cargo transports, and routine commuter flights to and from transportation nodes/depots located in LEO, LLO and LPO are examined and discussed 


\section{Benefits and Options for Using Lunar-Derived Propellants}

- Studies conducted by NASA and its contractors (early 1980's - early 1990's) indicated a substantial benefit from using lunar-derived propellants - specifically lunar-derived $\mathrm{LO}_{2}$ $\left(\mathrm{LLO}_{2}\right)$ or " $L U N O X$ ' in a lunar space transportation system (LTS)

- With a LTS using $\mathrm{LO}_{2} / \mathrm{LH}_{2}$ chemical rockets, $\sim 6$ kilograms $(\mathrm{kg})$ of mass in low Earth orbit (LEO) is required to place $1 \mathrm{~kg}$ of payload on the lunar surface (LS). Of this $6 \mathrm{~kg}, \sim 70 \%$ $(4.2 \mathrm{~kg})$ is propellant and $6 / 7^{\text {th }}$ of this mass $(3.6 \mathrm{~kg})$ is oxygen assuming an $\mathrm{O} / \mathrm{H} \mathrm{MR}=6: 1$

- Since the cost of placing a kilogram of mass on the LS is $\sim 6 \mathrm{X}$ the cost of delivering it to LEO, the ability to produce and utilize LUNOX or lunar-derived $\mathrm{LO}_{2}$ and hydrogen $\left(\mathrm{LLH}_{2}\right)$ from lunar polar ice (LPI) deposits can provide significant mission leverage

- Providing LUNOX for use in fuel cells, life support systems and $\mathrm{LO}_{2} / \mathrm{LH}_{2}$ chemical rockets used on lunar landing vehicles (LLVs), can allow "high value" cargo (people, manufacturing and scientific equipment, etc.) to be transported to LEO, then to the Moon instead of bulk $\mathrm{LO}_{2}$ propellant

- Oxygen is abundant in the lunar regolith ( $43 \%$ by mass) and can be extracted using a variety of techniques, such as hydrogen reduction of "ilmenite $\left(\mathrm{FeOTiO}_{2}\right)$ " or "FeO-rich" volcanic glass ("orange soil") discovered during the Apollo 17 mission to Taurus-Littrow

- While considerable interest has been expressed about mining and processing LPI for rocket propellant, "ground truth" must first be established to quantify the physical state of the ice (e.g., its vertical thickness and areal extent, levels of soil contamination, etc.) \& the deep, extremely cold ( $26-100 \mathrm{~K})$ permanently shadowed craters where the ice resides 


\section{D NITP \\ Volcanic Glass from the Apollo 17 Mission to Taurus-Littrow is Attractive for LUNOX Production}

"Propelling Us to New Worlds"

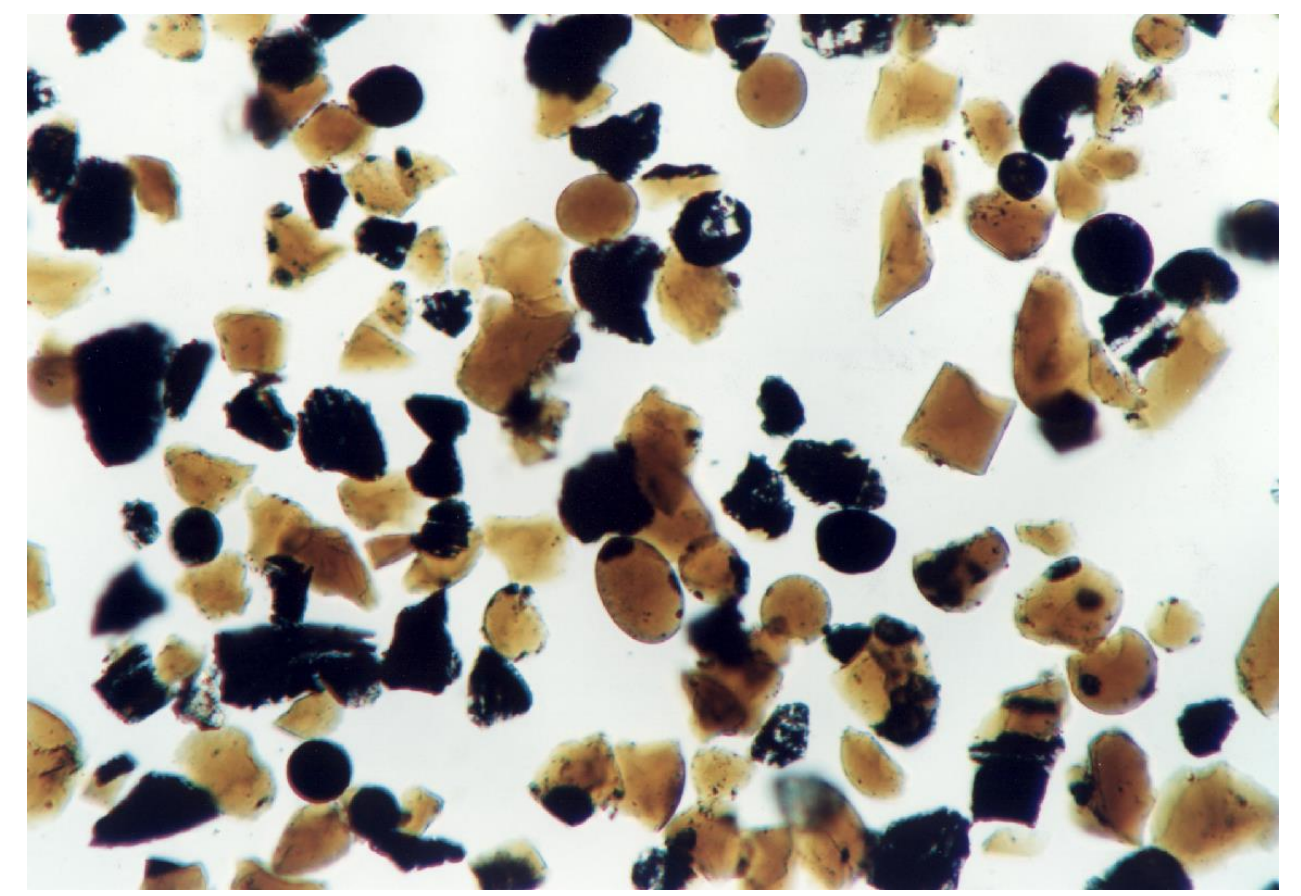

The best lunar oxygen ore found during the Apollo Program is the volcanic glass, found at Taurus-Littrow. The glass beads are fine grained and $\sim 40 \mathrm{~mm}$ in diameter. The orange beads are clear glass, while the black beads cooled at bit more slowly and had a chance to crystallize.

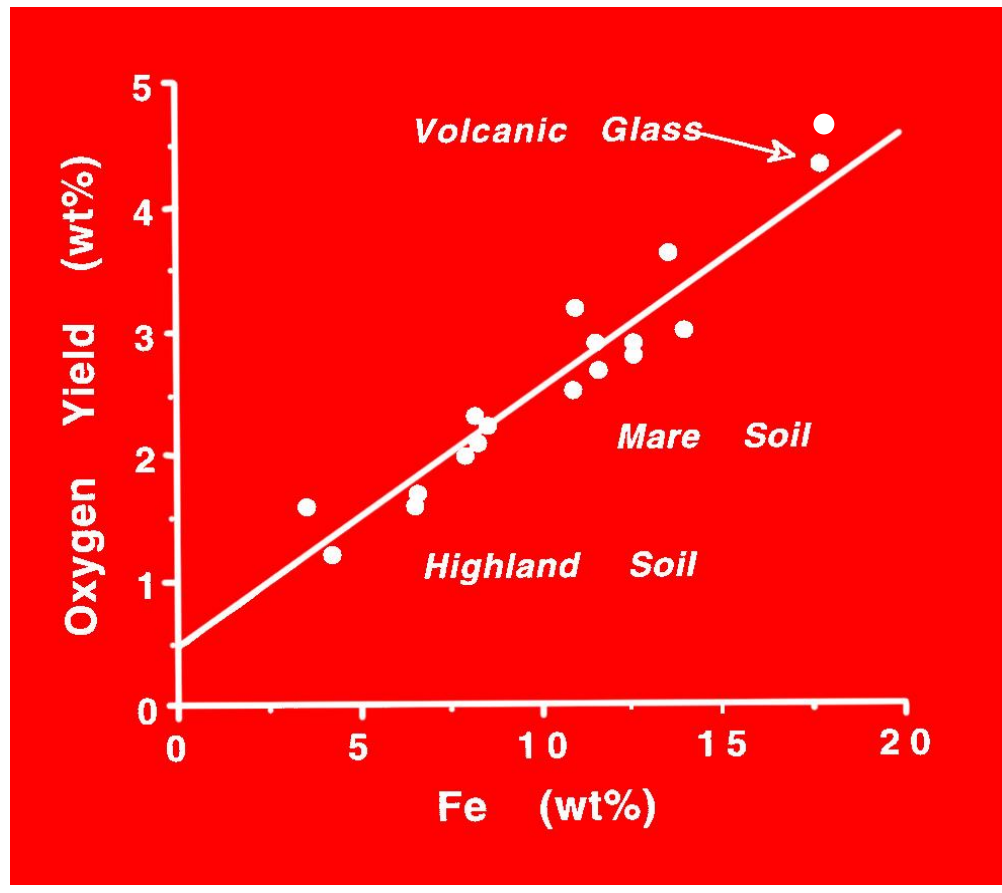

Oxygen yield is directly related to iron abundance for the full range of soil compositions. Highest yields are from " FeO-rich" volcanic glass.

\begin{tabular}{|c|c|}
\hline Oxygen production from "FeO-ric & olcanic glass is a 2 step process: \\
\hline $\begin{array}{l}\mathrm{FeO}+\mathrm{H}_{2}-\cdots--->\mathrm{Fe}+\mathrm{H}_{2} \mathrm{O} \\
\text { (Hydrogen Reduction \& Water Formation) }\end{array}$ & $\begin{array}{c}2 \mathrm{H}_{2} \mathrm{O}--->2 \mathrm{H}_{2}+\mathrm{O}_{2} \text { (LUNOX) } \\
\text { (Water Electrolysis \& Hydrogen Recycling) }\end{array}$ \\
\hline
\end{tabular}




\section{Scientific Evidence for Water Ice in Permanently Shadowed Craters (Cold Traps) Found in the Moon's Polar Regions}

- Since the 1960's, scientists have conjectured that water ice could survive in the cold, permanently shadowed craters located at the Moon's poles

- Clementine (1994), Lunar Prospector (1998), Chandrayaan-1 (2008), and Lunar Reconnaissance Orbiter (LRO) and Lunar CRater Observation and Sensing Satellite (LCROSS) (2009) lunar probes have provided data indicating the existence of large quantities of water ice at the lunar poles

- The Mini-SAR onboard Chandrayaan-1 discovered more than 40 permanently shadowed craters near the lunar north pole that are thought to contain $\sim 600$ million metric tons of water ice

- Using neutron spectrometer data, the Lunar Prospector science team estimated a water ice content $(\sim 1.5+/-0.8 \mathrm{wt} \%$ in the regolith) found in the Moon's polar "cold traps" and estimated the total amount of water at both poles at $\sim 2$ billion metric tons

- Using Mini-RF and spectrometry data, the LRO / LCROSS science team estimated the water ice content in the regolith in the south polar region to be $\sim 5.6+/-2.9 \mathrm{wt} \%$

- On the basis of the above scientific data, it appears that the water ice content can vary from $\sim 1-10 \mathrm{wt} \%$ and the total quantity of $\mathrm{LPI}$ at both poles can range from $\sim 600$ million to $\sim 2$ billion metric tons

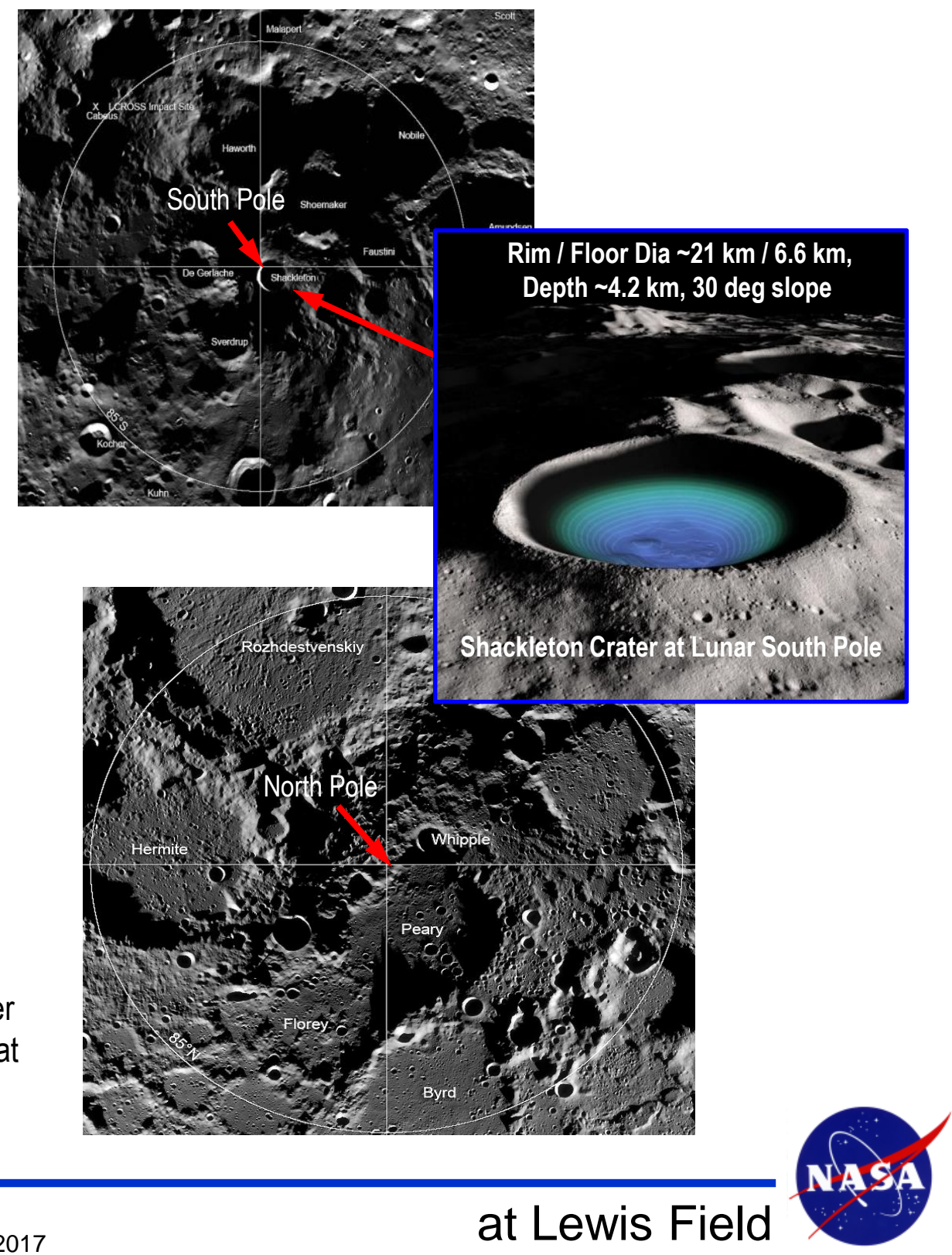




\section{Extracting Water Ice from Permanently Shadowed Craters in the Moon's Polar Regions will be Extremely Challenging}

- LPI deposits are important because they could supply both oxygen and hydrogen provided they can be economically accessed, mined, processed and stored for their desired use

- Higher $\Delta V$ s are required to access LPO sites and the candidate craters are deep, extremely cold, and exist in a state of perpetual darkness posing major challenges for the mining and processing of this cold, ice-cemented regolith material

- The world's 10 coldest mines are located in Russia's extreme northeastern territory. At the coldest of these mines, Sarylakh, the temperatures can drop to nearly $-50 \mathrm{C}(\sim 223 \mathrm{~K})$

- By contrast, the temperatures inside the polar craters, where the LPI is thought to exist, are $\sim 30-50 \mathrm{~K}$ - more than $5 \mathrm{x}$ colder than the coldest mines on Earth! At these temperatures, metals can become brittle

- Mining equipment must be able to break up, excavate and transport the ice-bearing regolith to the water extraction plant. It must also operate in a hard vacuum and be able to tolerate the abrasive nature of the lunar dust

- Experiments conducted by Gertsch et al. using $\mathrm{LN}_{2}$-cooled ice / regolith mixtures with $\sim 10 \mathrm{wt} \%$ water content indicate the mixture behaves like high strength concrete requiring heavy excavation equipment

- Once produced, the LPI-derived water would then be electrolyzed on the Moon and in space (at an orbiting propellant depot)

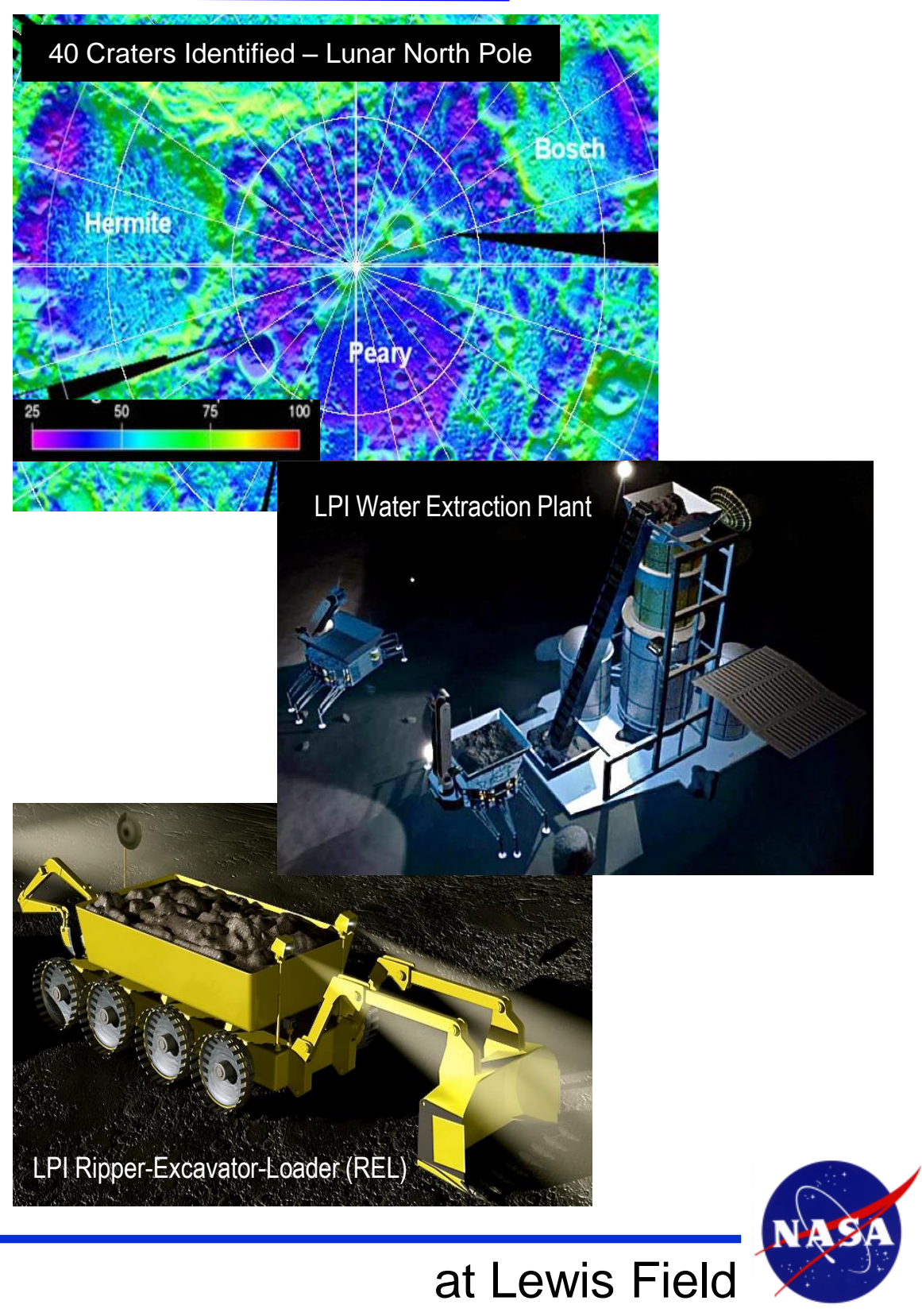




\section{Sampling of Crewed, Cargo \& Commercial Lunar Transfer Vehicle Concepts Developed by GRC During the Past 25 Years}

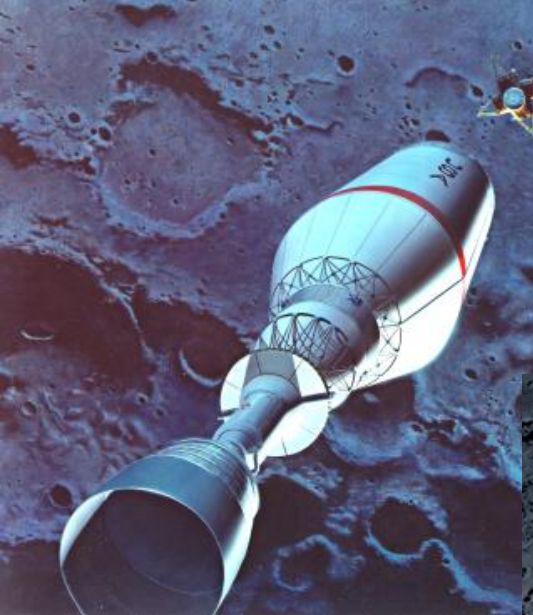

Reusable Lunar Transfer

Vehicle uses Single $75 \mathrm{klb}_{\mathrm{f}}$ NTR Engine - SEI (1990 - 91)

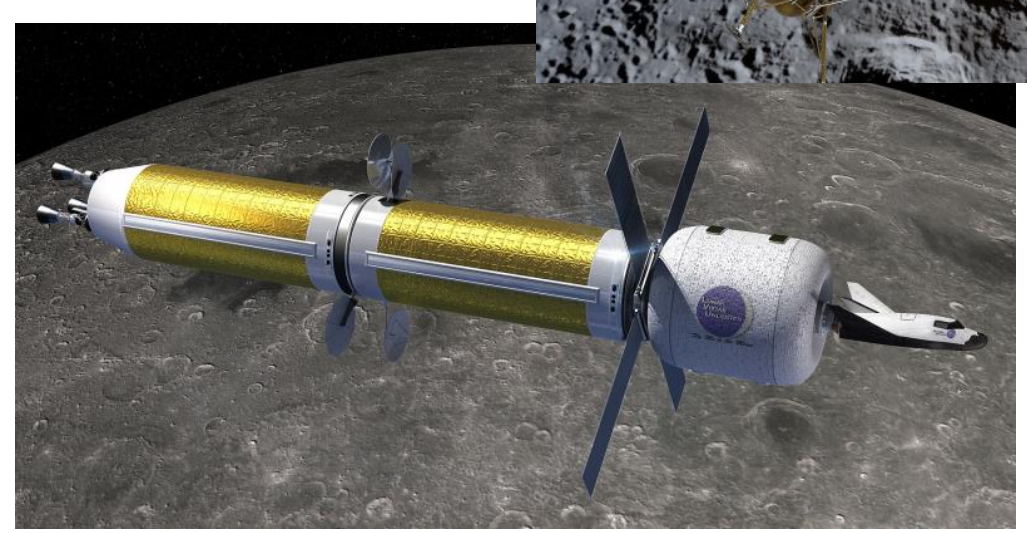

Commercial Tourism Polar Orbit Mission uses

$3-16.5 \mathrm{klb}_{\mathrm{f}}$ "SNRE-class" Engines - (2013-16)
Expendable TLI Stage for "First Lunar Outpost" Mission uses $3-25 \mathrm{klb}_{f}$ NTR Engines - Fast Track Study (1992)

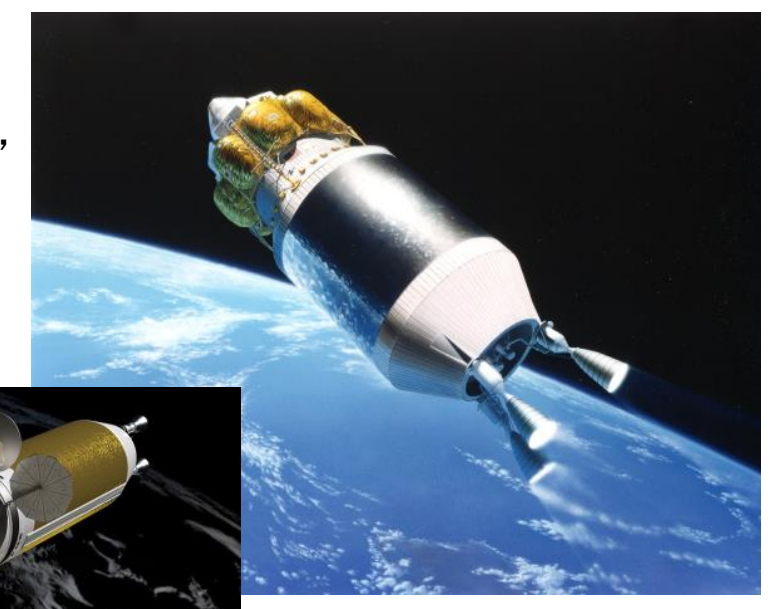

Reusable Lunar Cargo Transport uses $3-16.5 \mathrm{klb}_{\mathrm{f}}$ "SNRE-class" Engines - (2013-16)

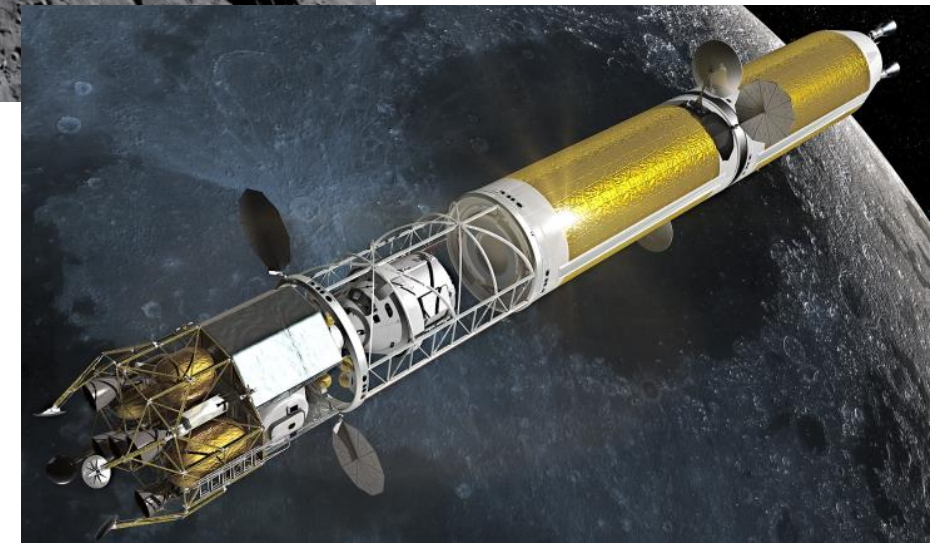

Reusable Crewed Landing Mission uses 3 - $16.5 \mathrm{klb}_{\mathrm{f}}$ “SNRE-class” Engines - (2013-16) 


\section{"Heritage" Fuel Element (FE) / Tie Tube (TT) Arrangement / Performance Parameters for Small Nuclear Rocket Engine}

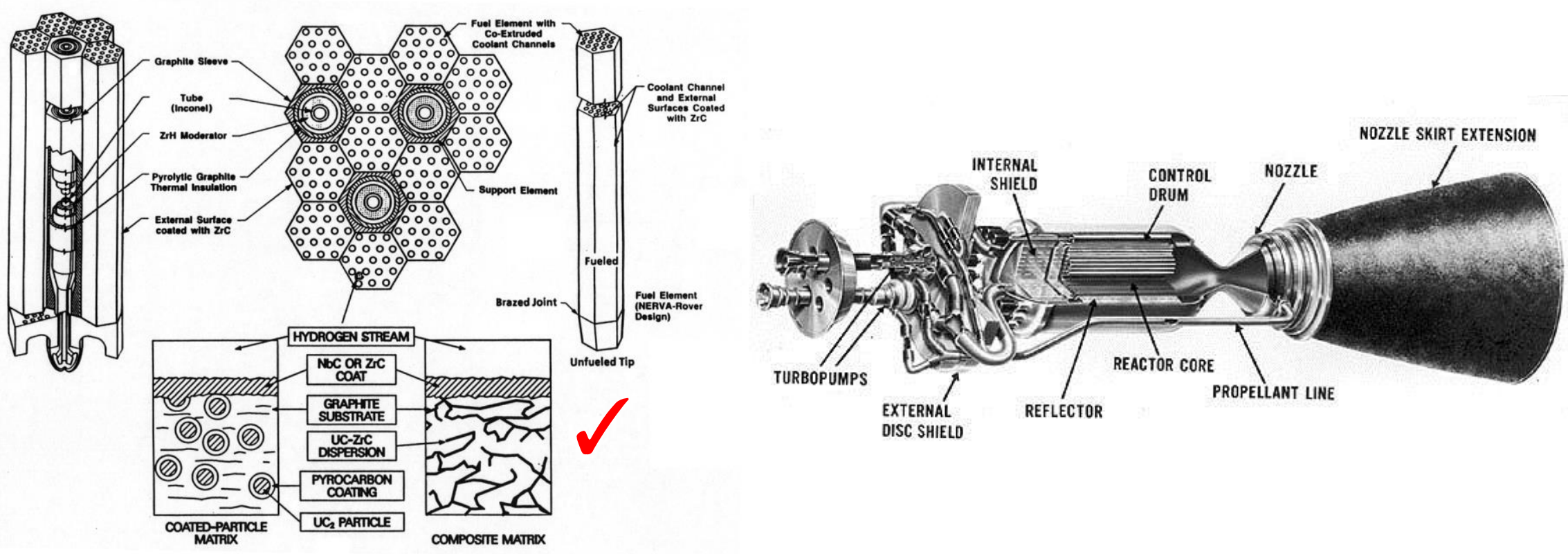

\begin{tabular}{|c|c|c|c|}
\hline \multicolumn{4}{|c|}{ Baseline Small Nuclear Rocket Engine (SNRE) Performance Parameters: } \\
\hline - Engine Cycle: Expander & • Thrust Level: 16.5 klb & - Reactor Exit Temperature: $2734 \mathrm{~K}$ & - Chamber Pressure: 1000 psia \\
\hline - Nozzle Area Ratio: 300:1 & - Specific Impulse $\left(I_{\mathrm{sp}}\right):$ 900 s & - Hydrogen Flow Rate: $~ 8.3 \mathrm{~kg} / \mathrm{s}$ & - F/ W eng Ratio: $~ 3.03$ \\
\hline • Engine Length: $5.8 \mathrm{~m}$ & • Nozzle Exit Diameter: $\sim 1.53 \mathrm{~m}$ & • FE Length $\sim 0.89 \mathrm{~m}$ ( $\sim 35$ inches) & • No. FEs / TTs: 564 / 241 \\
\hline - FE-to-TT Ratio: 2:1 & - Reactor Power Level: 365 MWt & • Fuel Matrix Power Density: $~ 3.44 \mathrm{I}$ & \\
\hline • U-235 Enrichment: 93\% & - Fuel Loading: $\sim 0.6$ grams $/ \mathrm{cm}^{3}$ & - U-235 Inventory: 60 kg & \\
\hline
\end{tabular}




\section{“LO ${ }_{2}$-Augmented” NTR (LANTR) Concept: Operational Features and Performance Characteristics}

LANTR adds an $\mathrm{O}_{2}$ "afterburner" nozzle and $\mathrm{O}_{2}$-rich $\mathrm{GG}$ feed system to a conventional NTR engine that provides a variable thrust and Isp capability, shortens burn times, extends engine life, and allows bipropellant operation

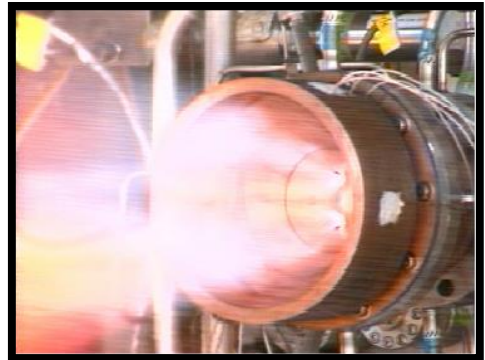

Aerojet / GRC Non-Nuclear $\mathrm{O}_{2}$ “Afterburner" Nozzle Test ${ }^{*}$

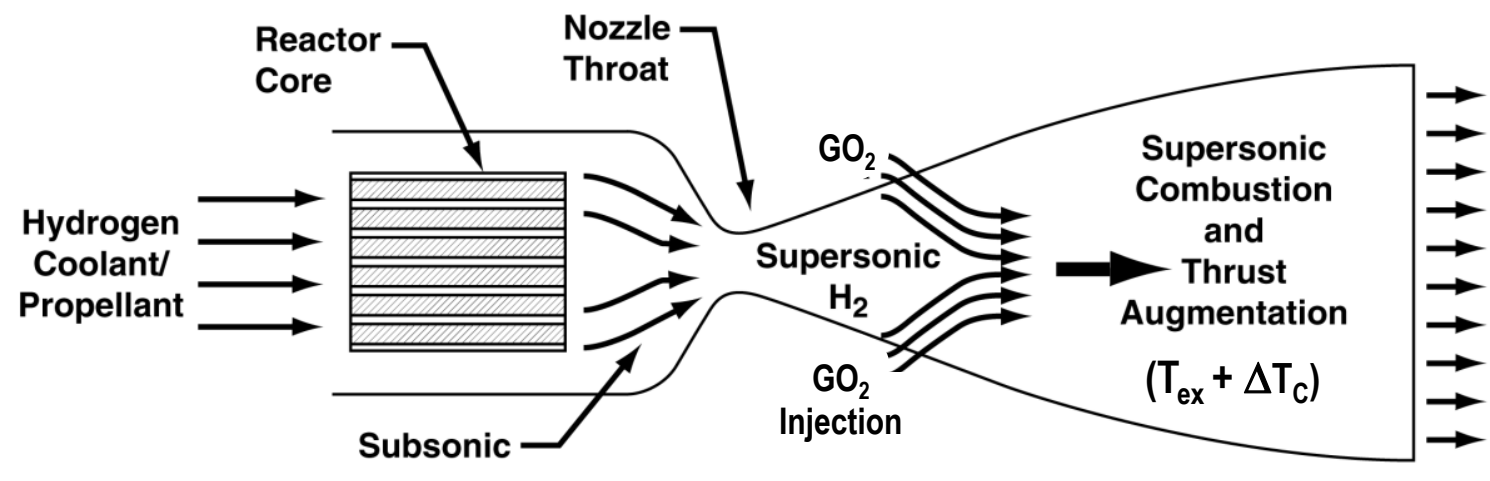

Hot $\mathrm{H}_{2}$ Exhaust $\left(\mathrm{T}_{\mathrm{ex}}\right)$

\begin{tabular}{|c|c|c|c|c|c|c|}
\hline O/H Mixture Ratio & 0 & 1 & 2 & 3 & 4 & 5 \\
\hline Delivered Isp $(\mathrm{s})$ & $900^{* *}$ & 725 & 637 & 588 & 552 & 516 \\
\hline $\begin{array}{c}\text { Thrust Augmentation } \\
\text { Factor }\end{array}$ & 1.0 & 1.611 & 2.123 & 2.616 & 3.066 & 3.441 \\
\hline Thrust $\left(\mathrm{Ib}_{\mathrm{f}}\right)$ & 16,500 & 26,587 & 35,026 & 43,165 & 50,587 & 56,779 \\
\hline Engine Mass $\left(\mathrm{Ib}_{\mathrm{m}}\right)$ & 5,462 & 5,677 & 5,834 & 5,987 & 6,139 & 6,295 \\
\hline Engine T/W & 3.02 & 4.68 & 6.00 & 7.21 & 8.24 & 9.02 \\
\hline
\end{tabular}

${ }^{* *}$ Fuel Exit Temperature $\left(T_{\text {ex }}\right)=2734^{\circ} \mathrm{K}$, Chamber Pressure $=1000$ psia and NAR $=300$ to 1 


\section{Variation in NLTV Size, IMLEO, Mission Capability and Burn Time Resulting from Use of $\mathrm{LLO}_{2}$ and Transition to LANTR Engines}

"Propelling Us to New Worlds"

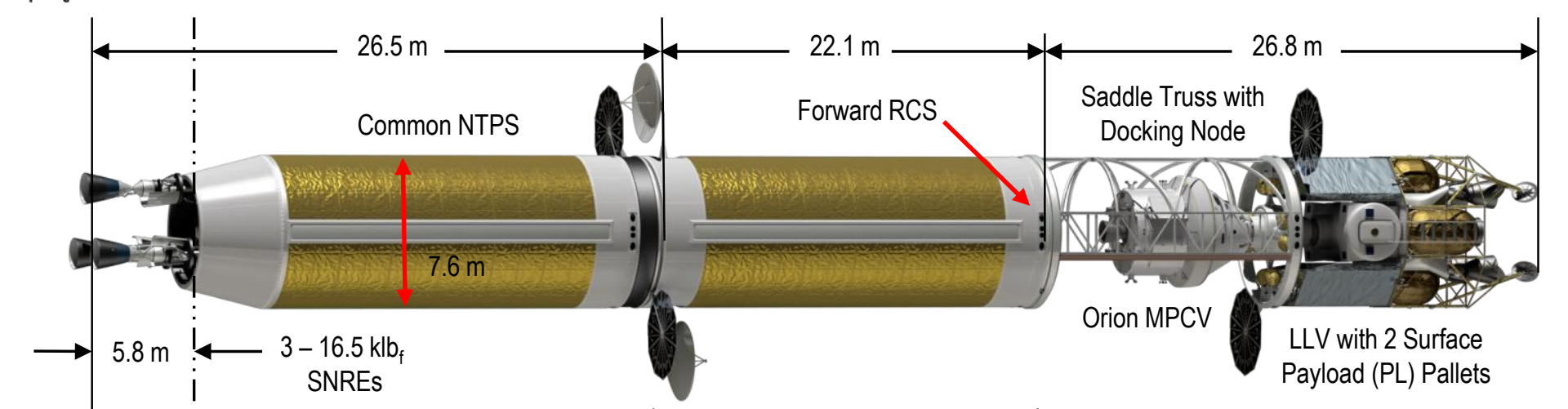

a) Crewed Lunar Landing: (LEO - LPO - 24-hr EEO)

- 4 crew

- MPCV + LLV $48 \mathrm{t}$

- IMLEO $182.4 \mathrm{t}$

- Max Lift 70 t (NTPS)

- Total Mission Burn

Time: $\sim 53.2 \mathrm{~min}$

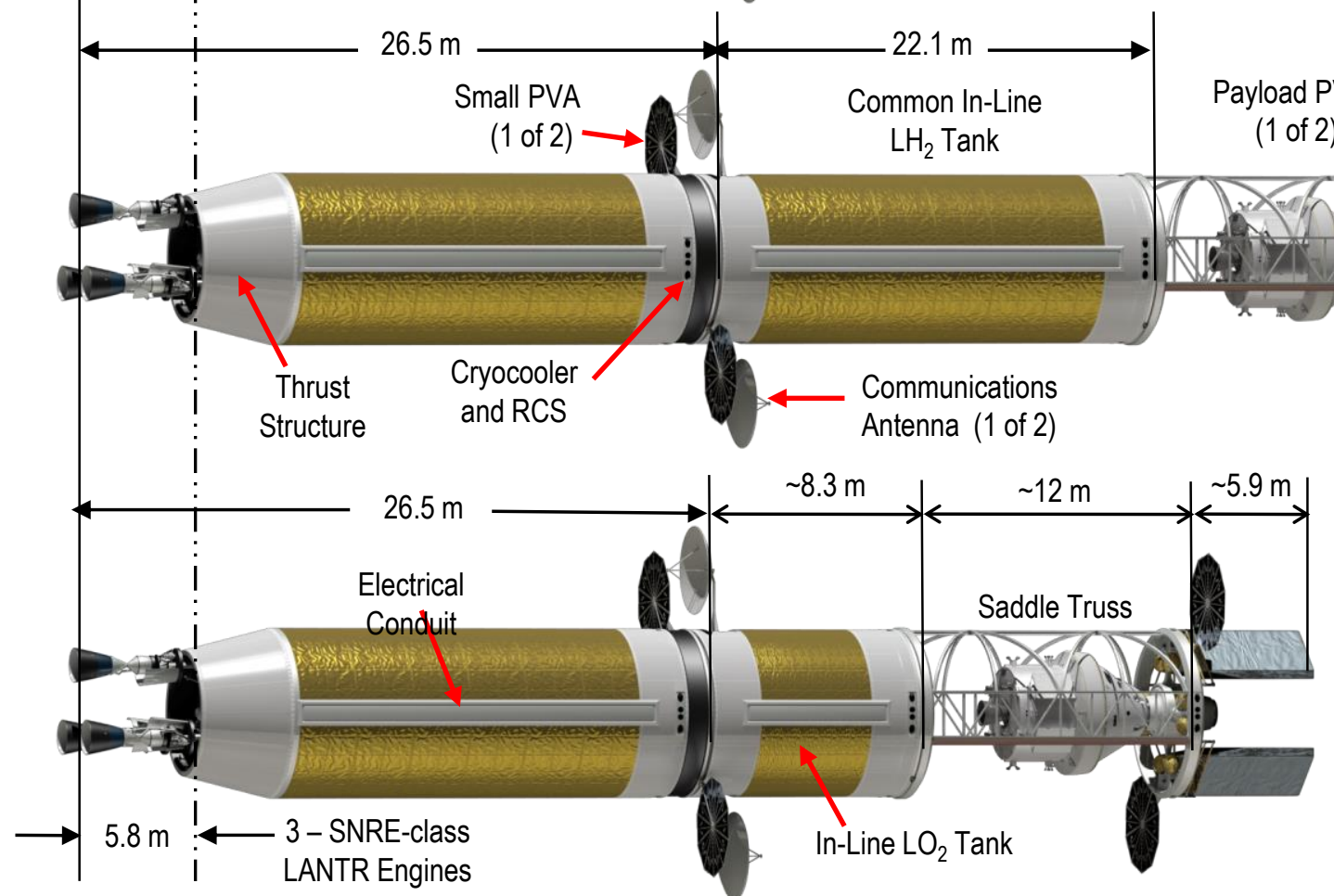

b) Crewed Lunar Landing: (LEO - LPO - 2.86-hr EEO) - MPCV + 4 crew + $5 \mathrm{t} \mathrm{PL}$

- Lunar Surface-based LLV

- IMLEO 152.2t

- Max Lift $~ 70$ t (NTPS)

- Total Mission Burn

Time: $\sim 53.2 \mathrm{~min}$

\section{c) Crewed Lunar Landing:}

(LEO - LPO - LEO)

- MPCV + 4 crew + 5 t PL

- Lunar Surface-based LLV

- IMLEO 133t

- Supplied LLO $251.4 \mathrm{t}$

- Supplied LLH $2 \sim 6.42 \mathrm{t}$

- Total Mission Burn

Time: $29.5 \mathrm{~min}$
Excess $\mathrm{LLH}_{2}$ from $\mathrm{H}_{2} \mathrm{O}$ electrolysis used to "top off" NTPS 


\section{Growth Mission Possibilities and Faster Trip Times using Depots and LUNOX Refueling}

Over time we envision the development of a totally space-based LTS with different types of NLTVs operating between transportation nodes I propellant depots located in LEO, equatorially LLO and LPO.
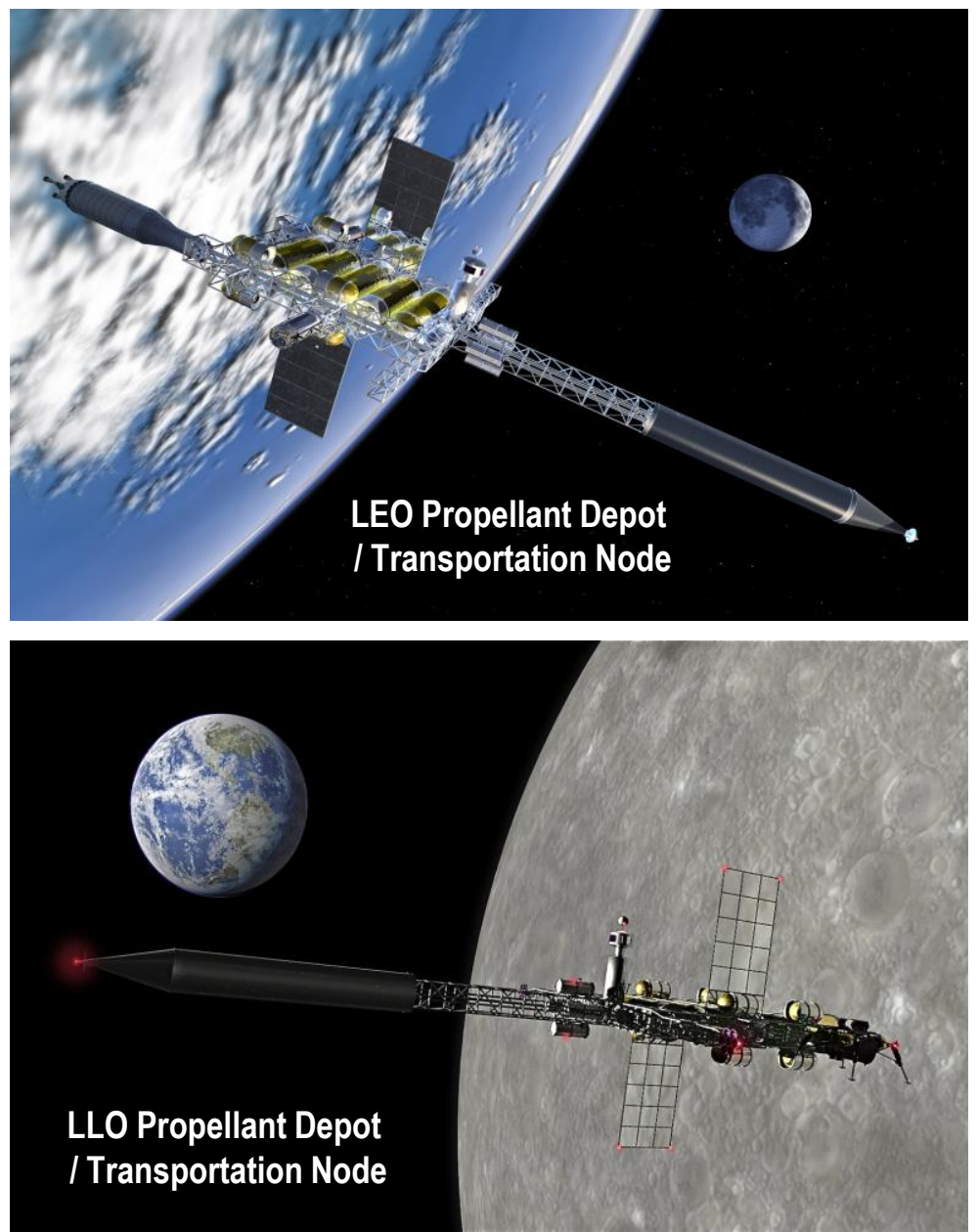

One-way transit times to and from the Moon on the order of 72 hours would be the norm initially. As lunar outposts grow into settlements staffed by visiting scientists, engineers and administrative personnel representing both government and private ventures, more frequent flights of shorter duration could become commonplace.

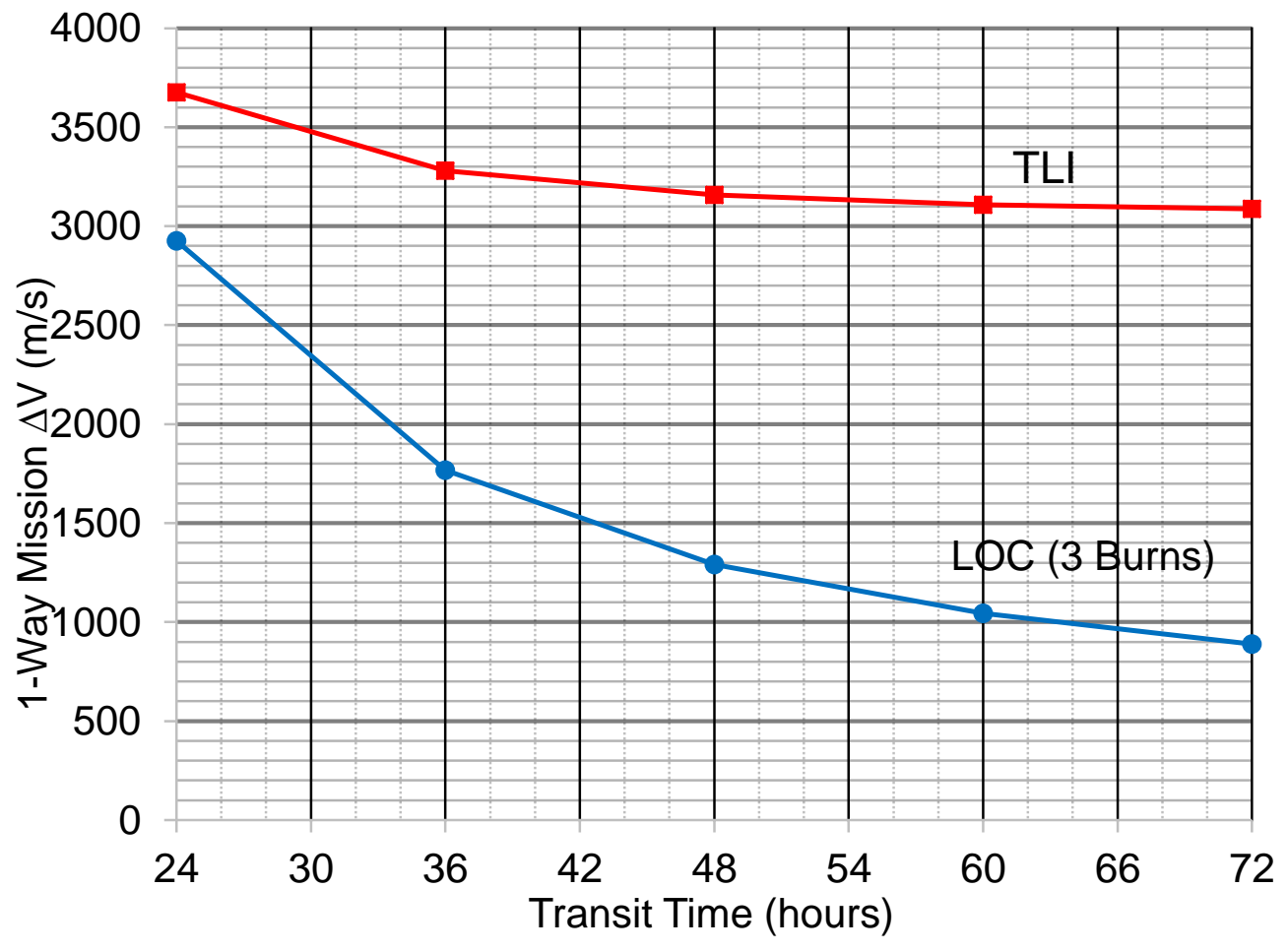

Cutting the Earth-Moon transit times in half to $\sim 36$ hours will require the mission's total $\Delta V$ budget to increase by $\sim 25 \%-$ from $\sim 8$ to $10 \mathrm{~km} / \mathrm{s}$. For 24 hour LEO to LPO transit times the total mission $\Delta \mathrm{V}$ increases by $\sim 63 \%$ - from $\sim 8$ to $13 \mathrm{~km} / \mathrm{s}$. 


\section{Conestoga - LANTR-propelled Crewed Cargo Transport uses a "Common" NTPS and In-Line $\mathrm{LO}_{2}$ Tank Assembly}

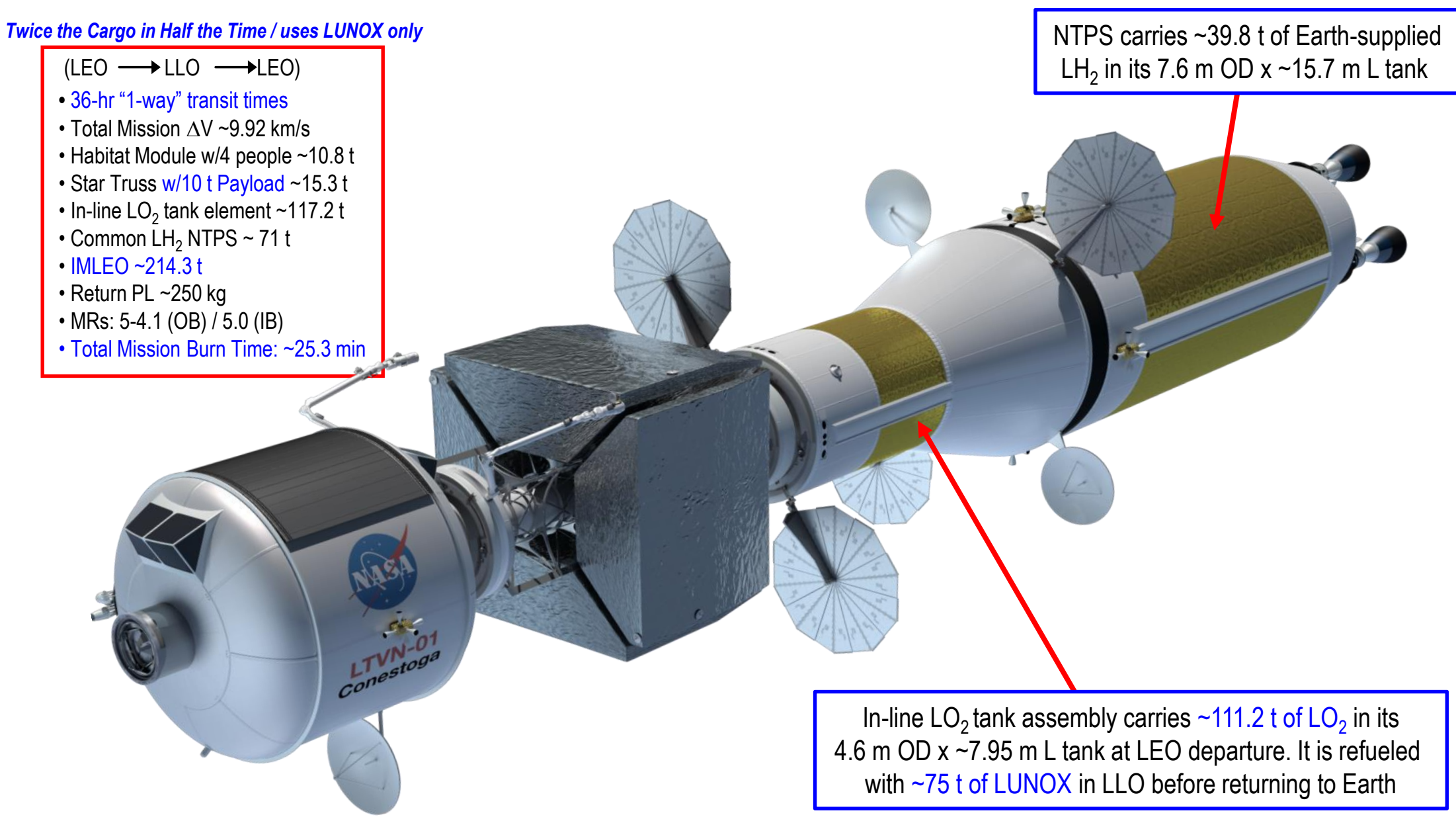

\section{Glenn Research Center}




\section{Conestoga - LANTR-propelled Crewed Cargo Transport uses a "Common" NTPS and In-Line $\mathrm{LO}_{2}$ Tank Assembly}

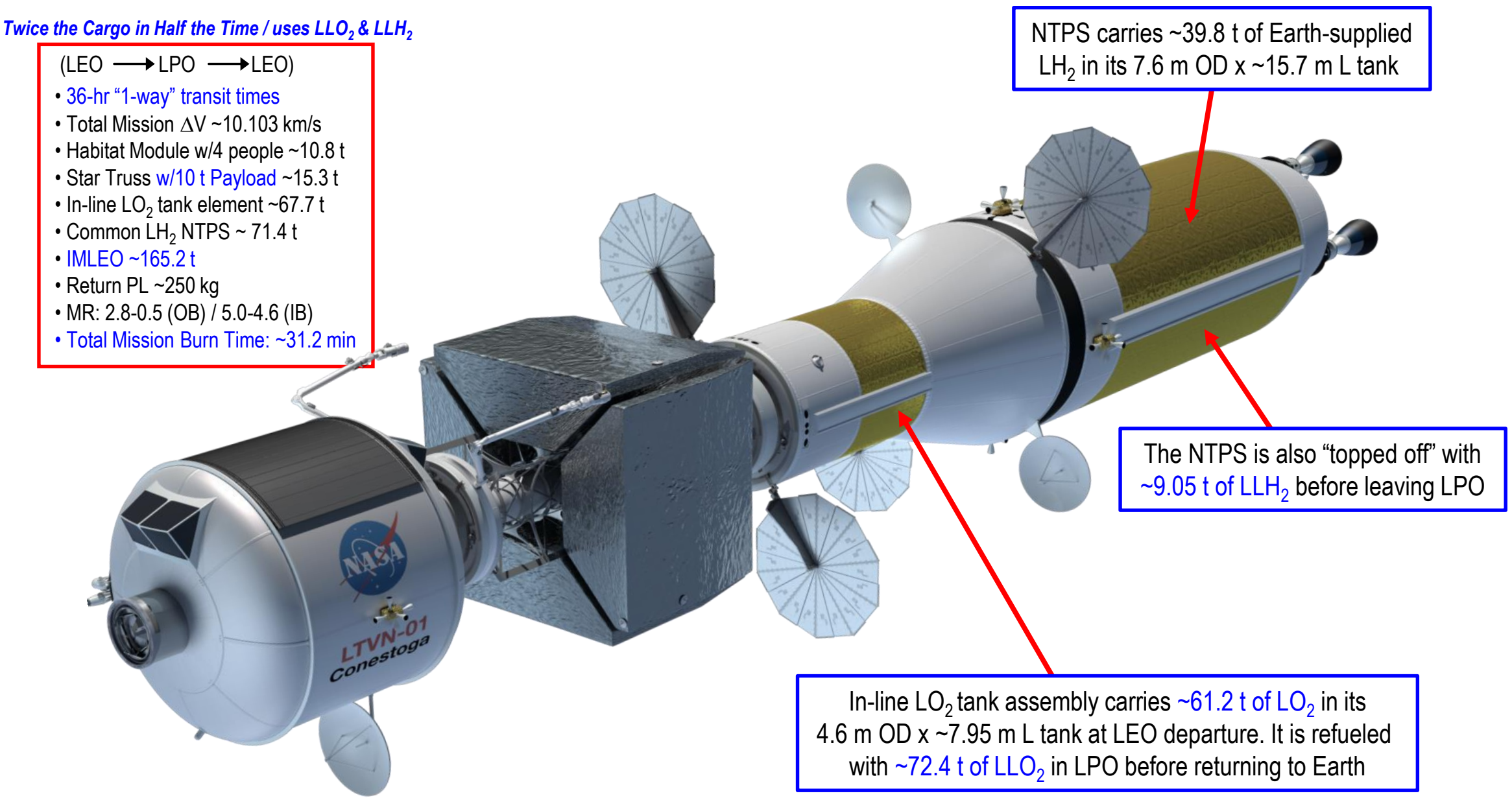

\section{Glenn Research Center}




\section{Conestoga-II - LANTR-propelled Heavy Crewed Cargo Transport uses a "Common" NTPS, In-Line LO, Tank Assembly and $2^{\text {nd }}$ Star Truss}

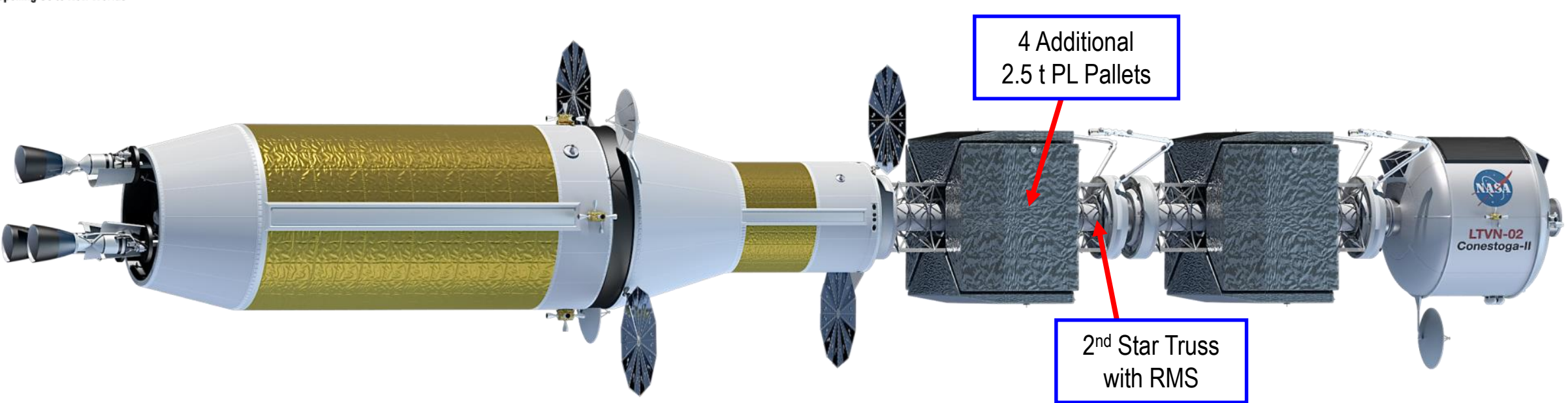

Double the PL: 10 to 20 t / LUNOX only

(LEO $\longrightarrow$ LLO $\longrightarrow$ LEO)

- 72-hr "1-way" transit times

- Total Mission $\Delta \mathrm{V} \sim 8.057 \mathrm{~km} / \mathrm{s}$

- Habitat Module w/4 people $\sim 10.8 \mathrm{t}$

- 2 Star Trusses w/20 t PL 30.6 t

- In-line $\mathrm{LO}_{2}$ tank element $\sim 77.1 \mathrm{t}$

(initial LEO-supplied $\mathrm{LO}_{2} \sim 71 \mathrm{t}$ )

- Common $\mathrm{LH}_{2}$ NTPS $~ 71.1 \mathrm{t}$

- IMLEO 189.6 t

- Refueled $\mathrm{LLO}_{2} \sim 52.1 \mathrm{t}$

- Return PL $\sim 250 \mathrm{~kg}$

- MRs Used: TLI (MR 3.4, I $\sim$ sp 573 s); LOC (MR 0.9, I $\left.\mathrm{I}_{\mathrm{sp}} \sim 737 \mathrm{~s}\right)$; TEI (MR 4.7, $\left.\mathrm{I}_{\mathrm{sp}} \sim 527 \mathrm{~s}\right)$; EOC (MR 3.8, $\left.\mathrm{I}_{\mathrm{sp}} \sim 558 \mathrm{~s}\right)$

- Total Mission Burn Time: $\sim 25.3 \mathrm{~min}$

Deliver 20 t PL w/LLO ${ }_{2} / \mathrm{LLH}_{2}$ refueling

(LEO $\longrightarrow$ LPO $\longrightarrow$ LEO)

- Total Mission $\Delta \mathrm{V} \sim 8.081 \mathrm{~km} / \mathrm{s}$

- Habitat Module w/4 people $\sim 10.8 \mathrm{t}$

- 2 Star Trusses w/20 t PL 30.6 t

- In-line $\mathrm{LO}_{2}$ tank element $\sim 59.9 \mathrm{t}$

(initial LEO-supplied $\mathrm{LO}_{2} \sim 52.7 \mathrm{t}$ )

- Common $\mathrm{LH}_{2}$ NTPS $~ 72.1 \mathrm{t}$

- IMLEO 173.4 t

- Refueled $\mathrm{LLO}_{2} \sim 47.5 \mathrm{t}$

- Refueled $\mathrm{LLH}_{2} \sim 5.93 \mathrm{t}$

- Return PL $\sim 250 \mathrm{~kg}$

- MRs Used: TLI (MR 2.5, $\mathrm{I}_{\mathrm{sp}} \sim 612 \mathrm{~s}$ ); LOC (MR 0, $\left.\mathrm{I}_{\mathrm{sp}} \sim 900 \mathrm{~s}\right)$; TEl (MR 4.4 $\left.\mathrm{I}_{\mathrm{sp}} \sim 537 \mathrm{~s}\right)$; EOC (MR 3.1, $\left.\mathrm{I}_{\mathrm{sp}} \sim 585 \mathrm{~s}\right)$

- Total Mission Burn Time: $29.1 \mathrm{~min}$

Double the PL: 20 to $40 \mathrm{t}$ / LUNOX only

(LEO $\longrightarrow$ LLO $\longrightarrow$ LEO)

- 72-hr "1-way" transit times

- Total Mission $\Delta \mathrm{V} \sim 8.064 \mathrm{~km} / \mathrm{s}$

- Habitat Module w/4 people $~ 10.8 \mathrm{t}$

- 2 Star Trusses w/40 t PL 52.7 t

- In-line $\mathrm{LO}_{2}$ tank element $\sim 116 \mathrm{t}$

(initial LEO-supplied LO $2109.8 \mathrm{t}$ )

- Common $\mathrm{LH}_{2}$ NTPS $71.2 \mathrm{t}$

- IMLEO 250.7 t

- Refueled $\mathrm{LLO}_{2} \sim 60.3 \mathrm{t}$

- Return PL 250 kg

- MRs Used: TLI (MR 4.4, I $\left.\mathrm{I}_{\mathrm{sp}} \sim 536 \mathrm{~s}\right)$; LOC (MR 3.3, $\mathrm{I}_{\mathrm{sp}} \sim 578 \mathrm{~s}$ ); TEl (MR 5.0, $\left.\mathrm{I}_{\mathrm{sp}} \sim 516 \mathrm{~s}\right)$; EOC (MR 4.8, $\left.\mathrm{I}_{\mathrm{sp}} \sim 522 \mathrm{~s}\right)$

- Total Mission Burn Time: $\sim 25.2 \mathrm{~min}$
Deliver $40 \mathrm{t} P L \mathrm{w} / \mathrm{LLO}_{2} / \mathrm{LLH}_{2}$ refueling

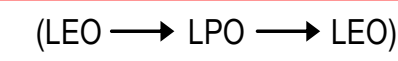

- 72-hr "1-way" transit times

- Total Mission $\Delta \mathrm{V} \sim 8.092 \mathrm{~km} / \mathrm{s}$

- Habitat Module w/4 people $~ 10.8 \mathrm{t}$

- 2 Star Trusses w/40 t PL 52.7 t

- In-line $\mathrm{LO}_{2}$ tank element $\sim 81.7 \mathrm{t}$

(initial LEO-supplied $\mathrm{LO}_{2} \sim 74.3 \mathrm{t}$ )

- Common $\mathrm{LH}_{2}$ NTPS $72.4 \mathrm{t}$

- IMLEO 217.6 t

- Refueled $\mathrm{LLO}_{2} \sim 57.2 \mathrm{t}$

- Refueled LLH $2 \sim 7.15 \mathrm{t}$

- Return PL 250 kg

- MRs Used: TLI (MR 2.9, I I $2594 \mathrm{~s})$; LOC (MR 0.5, $\mathrm{I}_{\mathrm{sp}} \sim 795 \mathrm{~s}$ ); TEl (MR 5, $\left.\mathrm{I}_{\mathrm{sp}} \sim 516 \mathrm{~s}\right) ; \operatorname{EOC}\left(\mathrm{MR} \sim 4.3, \mathrm{I}_{\mathrm{sp}} \sim 543 \mathrm{~s}\right)$

- Total Mission Burn Time: $29.9 \mathrm{~min}$ 


\section{Relative Size of the Conestoga Crewed Cargo Transport and Passenger Commuter Shuttle}

"Propelling Us to New World

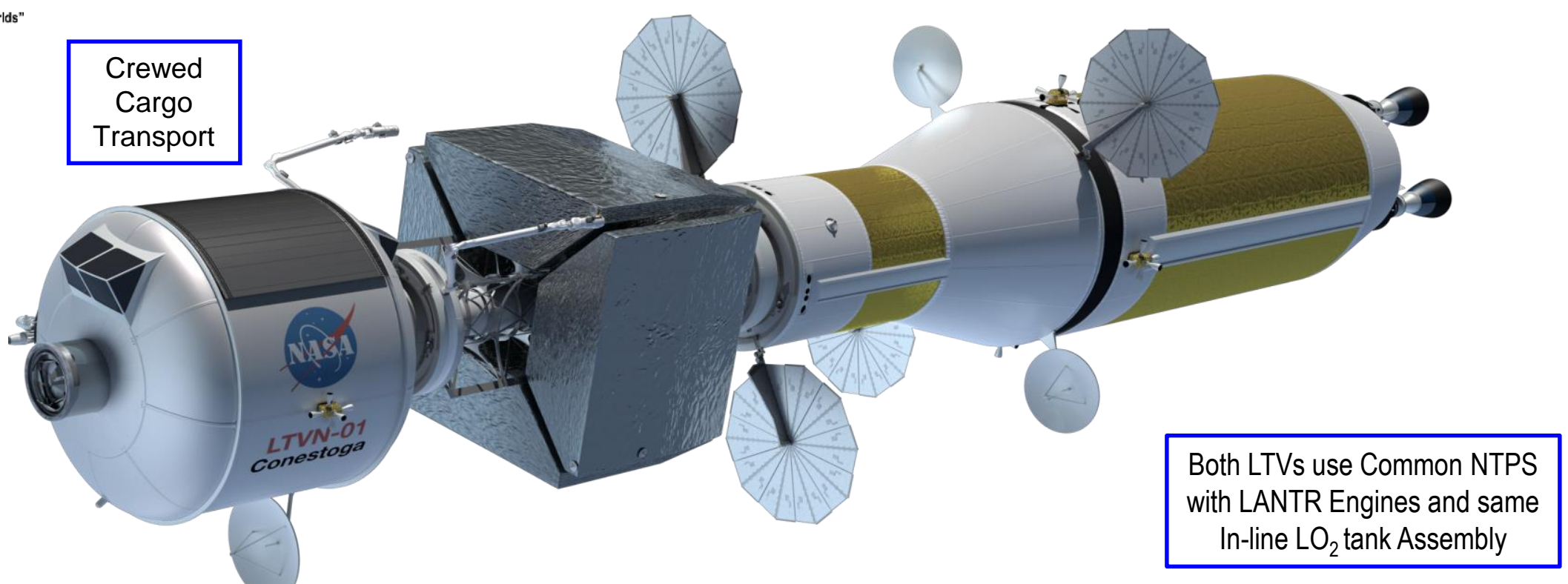

For Commuter Shuttle Missions, the
Habitat Module, Saddle Truss and
its attached Payload are replaced with
a Passenger Transport Module (PTM)

\section{Glenn Research Center}




\section{How Might a Typical Commuter Flight to the Moon Proceed?}

A possible scenario might start with passengers boarding a future "Earth-to-Orbit" shuttle for a flight to a future International Space Station (ISS) with artificial gravity capability. There they would enter a Passenger Transport Module (PTM) containing its own life support, power, instrumentation and control, and RCS. The PTM provides the "brains" for the LANTR-powered shuttle and is home to the 18 passengers and 2 crewmembers operating it while on route to the Moon. After departing the ISS, the PTM docks with the fully fueled LANTR shuttle awaiting it a safe distance away.
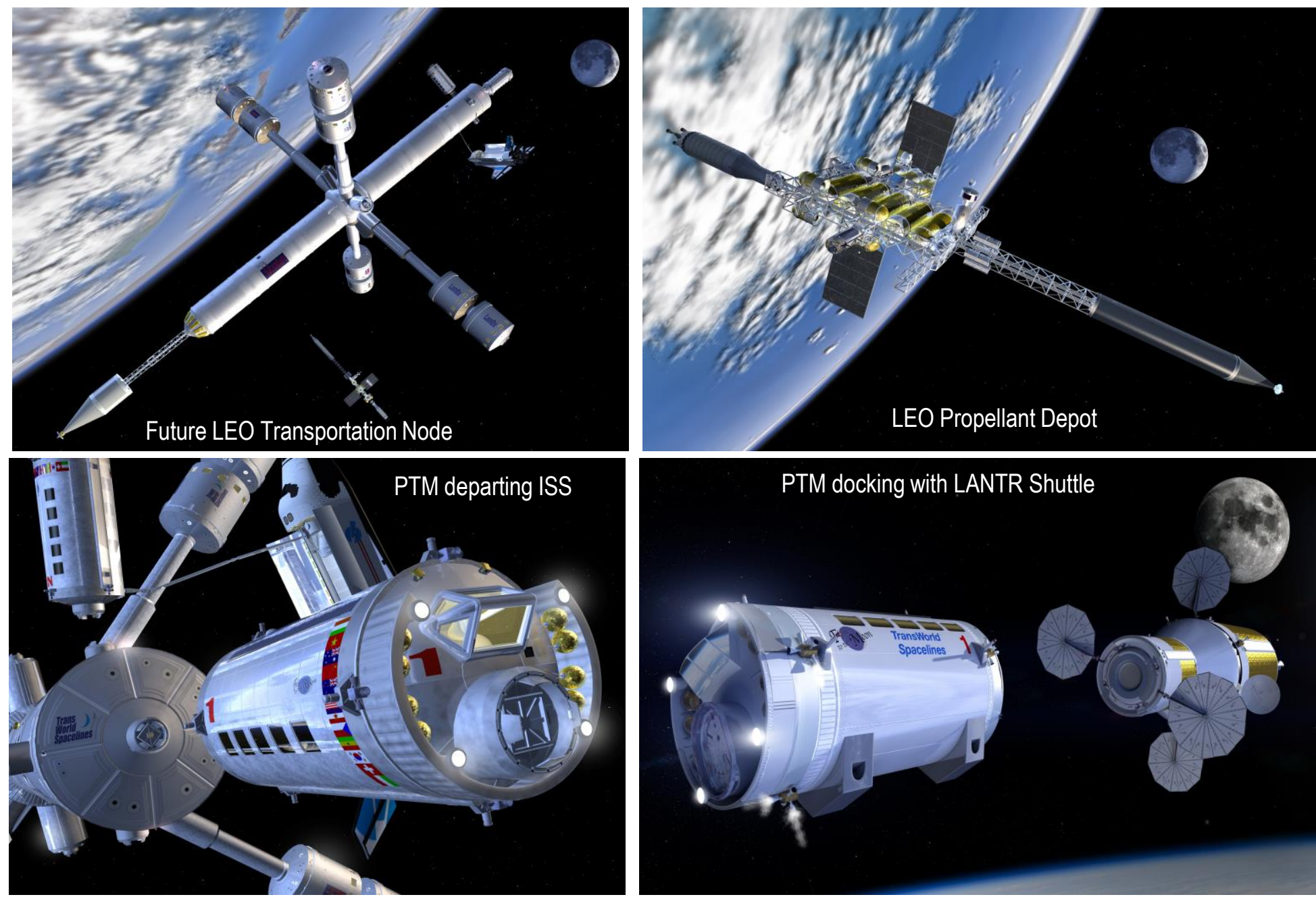

\section{Glenn Research Center}




\section{How Might a Typical Commuter Flight to the Moon Proceed?}

At the appropriate moment, the LANTR engines are powered up and the shuttle climbs rapidly away from Earth. After a 1-1.5-day transfer, the LANTR shuttle arrives in LLO where the PTM detaches and docks with a "Sikorsky-style" LLV awaiting it in LLO. After its delivery to the lunar surface, the PTM is lowered to a "flat-bed" surface vehicle and electronically engaged providing the PTM with surface mobility. The PTM then drives itself to the lunar base airlock for docking and passenger unloading. This scenario is reversed on the return trip back to Earth.
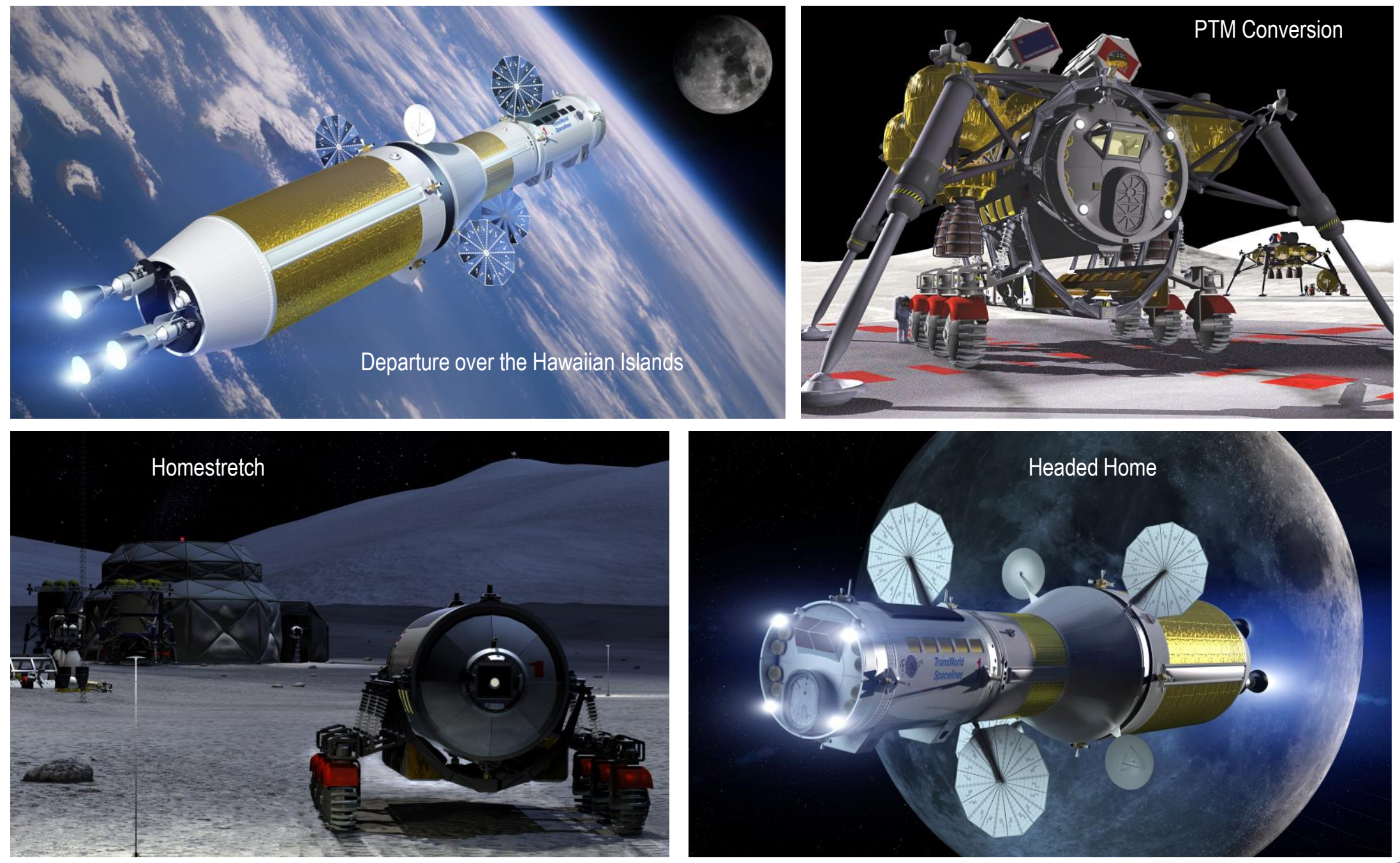


\section{LANTR Commuter Shuttle Mission Options, Trip Time and $\Delta \mathrm{V}$ Budgets, and LDP Refueling Requirements}

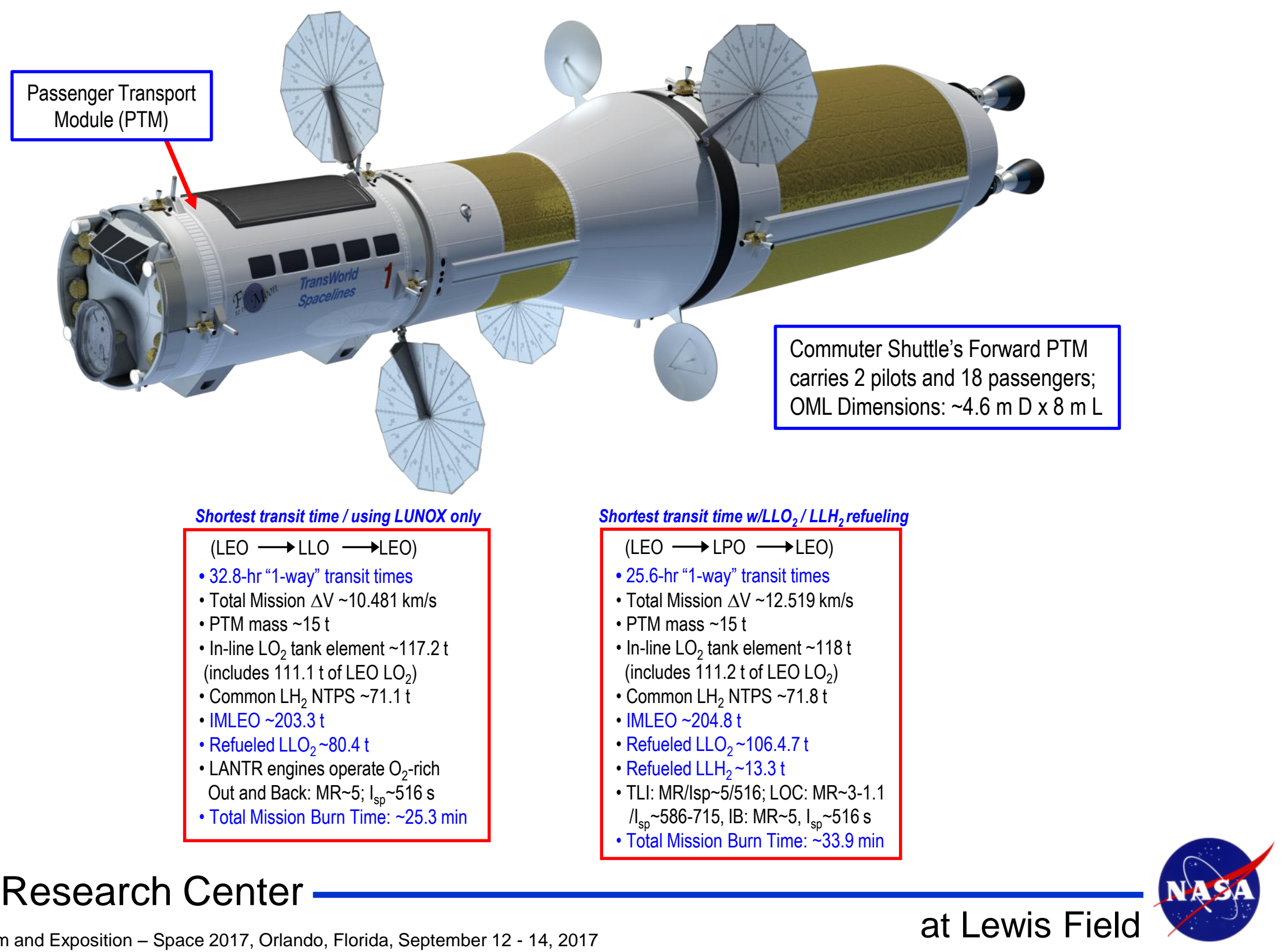




\section{LANTR Commuter Shuttle Mission Options, Trip Time and $\Delta \mathrm{V}$ Budgets, and LDP Refueling Requirements}

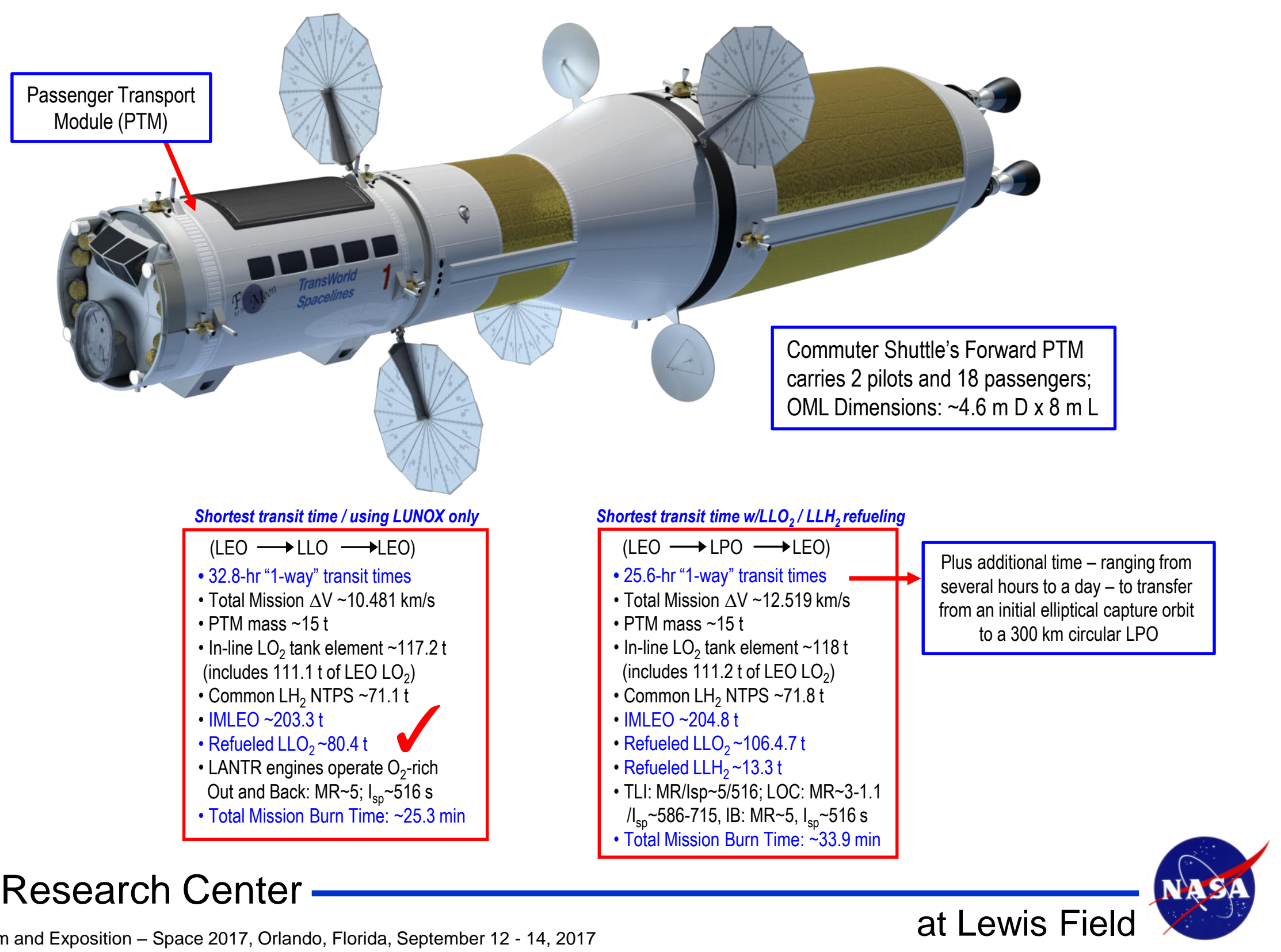




\section{$\underline{\text { Total LUNOX Required for "Weekly" Commuter Flights }}$}

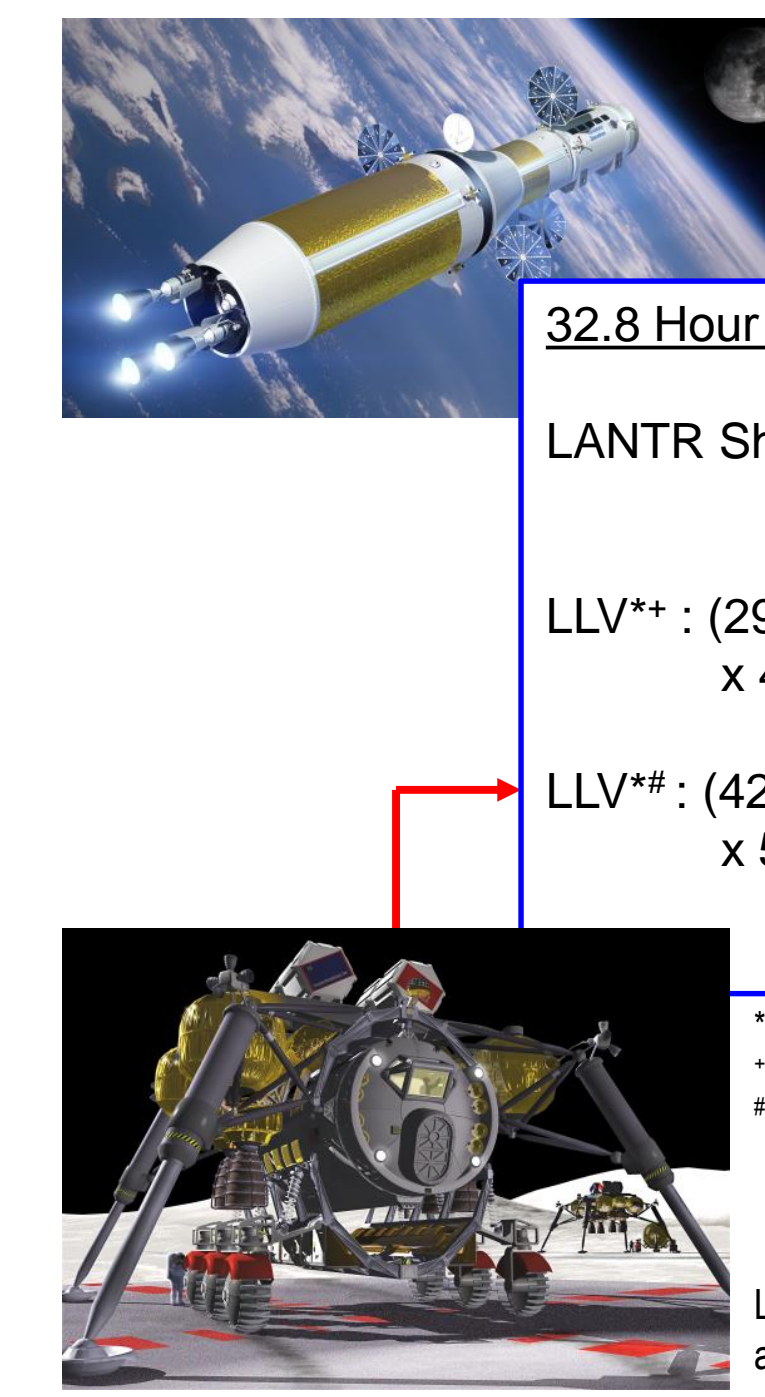

LANTR Shuttle

Departing LEO

for the Moon
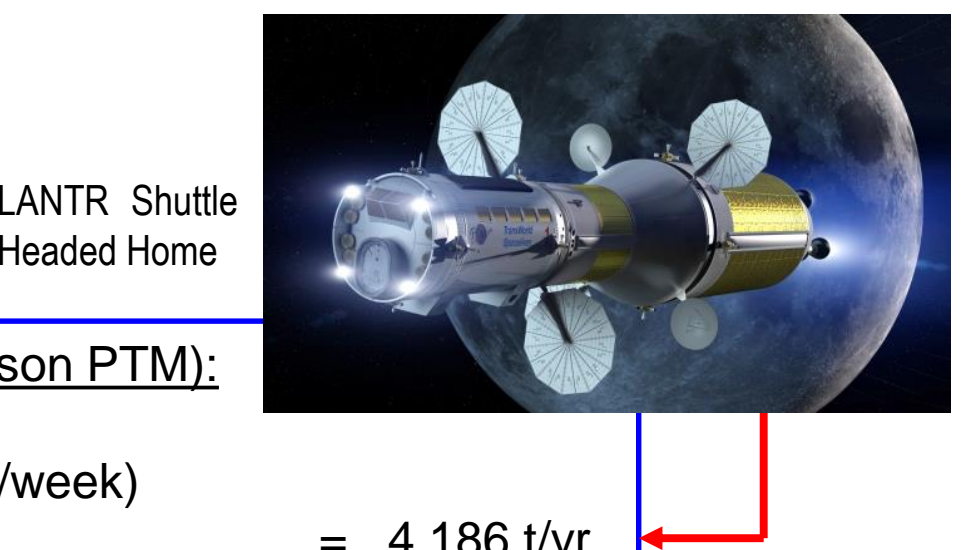

$$
\text { x } 52 \text { weeks/year }
$$$$
=4,186 \mathrm{t} / \mathrm{yr}
$$

9.5 t LUNOX / flight ${ }^{+}$) x (1 flight/LLV/week)

x 4 LLVs x 52 weeks/year

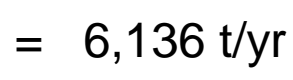

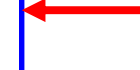

\# round trip fir x 52 weeks /year

$=\underline{2,220 \mathrm{t} / \mathrm{yr}}$

Total LUNOX Rate $=12,542 \mathrm{t} / \mathrm{yr}$

${ }^{*} \mathrm{O} / \mathrm{H} \mathrm{MR}=6, \mathrm{I}_{\mathrm{sp}}=465 \mathrm{~s}, \Delta \mathrm{V}_{\text {desc }}=2000 \mathrm{~m} / \mathrm{s}$ and $\Delta \mathrm{V}_{\text {asc }}=1900 \mathrm{~m} / \mathrm{s}$ assumed

+ LLV tanker transports $\sim 25 \mathrm{t}$ of LUNOX to LLO; returns to LS with empty $5 \mathrm{t}$ tank

\#Total for LLV delivery of PTM from LLO to LS plus PTM return from the LS to LLO

LLV Unloading PTM onto

a Mobile Surface Vehicle
Tanker LLV Delivering LUNOX to LLO Depot

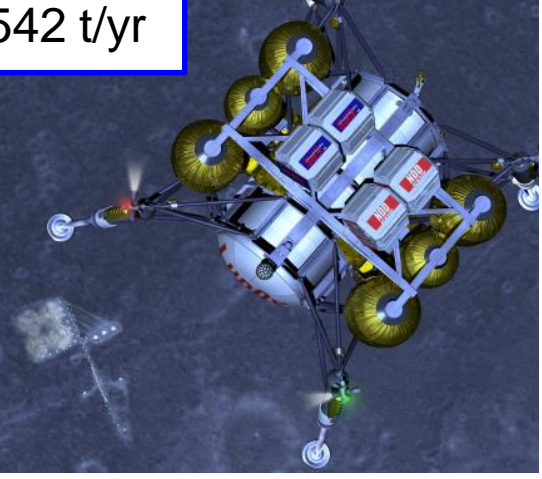




\section{Mining Area and LUNOX Production Rates Required to Support Weekly Commuter Flights to the Moon}

At the SE edge of the "Sea of Serenity" lies the Taurus-Littrow DMD of FeO-rich black crystalline and orange glass beads. The deposit is vast $\left(\sim 3000 \mathrm{~km}^{2}\right)$ and tens of meters thick.

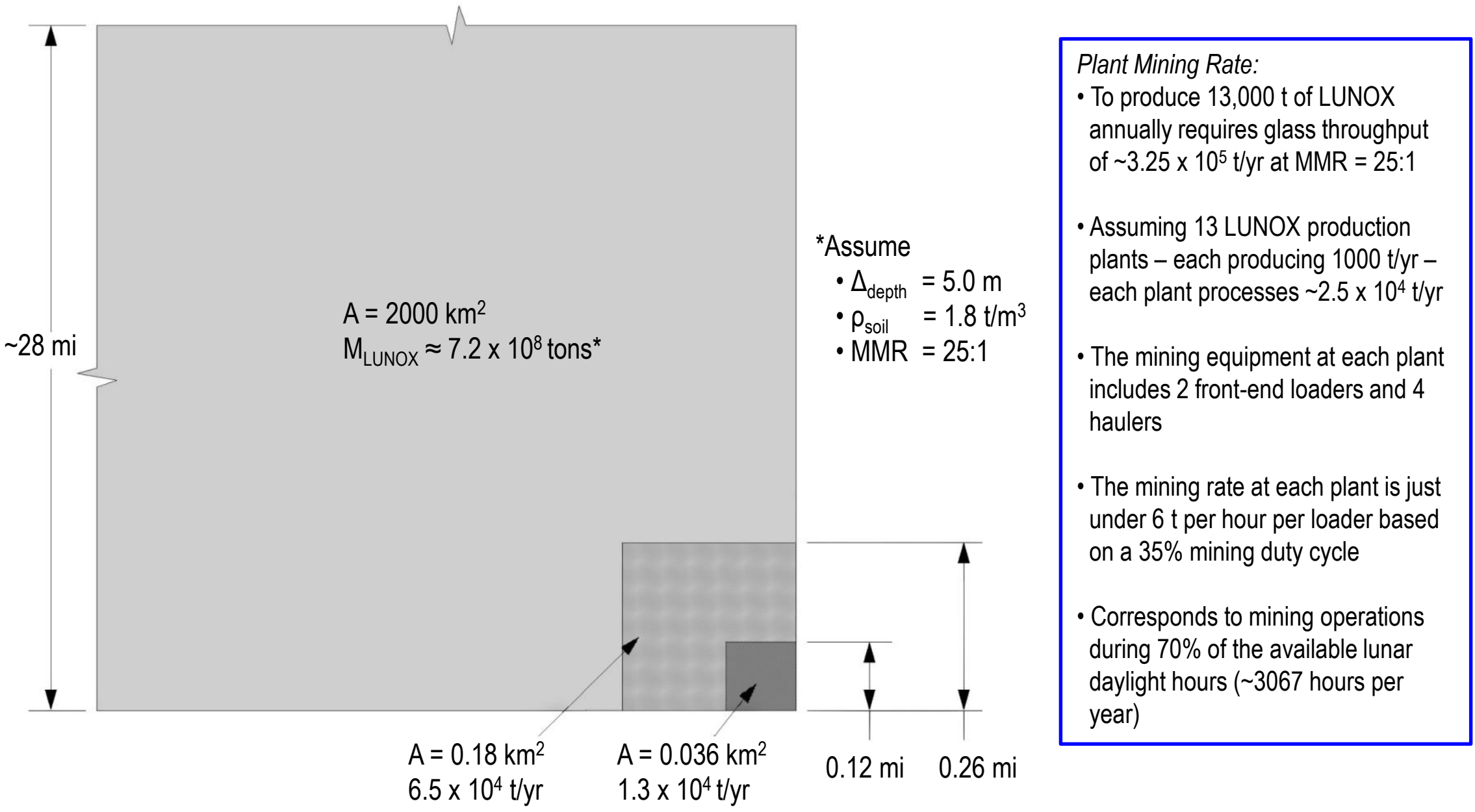

\footnotetext{
Could supply LUNOX for 25 commuter flights carrying 450 passengers each week for next 2215 yrs!
} 


\section{Summary, Concluding Remarks, and a Look Ahead}

- NTP offers significant benefits for lunar missions and can take advantage of the leverage provided from using LDPs - "when they become available" - by transitioning to LANTR propulsion. LANTR provides a variable thrust and $I_{s p}$ capability, shortens burn times and extends engine life, and allows bipropellant operation

- The combination of LANTR and LDP has performance capability equivalent to that of a hypothetical "gaseous fuel core" NTR (effective $I_{\text {sp }} \sim 1575 \mathrm{~s}$ ) and can lead to a robust LTS with unique mission capabilities that include short transit time crewed cargo transports and routine commuter flights to the Moon

- The biggest challenge to making this vision a reality will be the production of increasing amounts of LDP and the development of propellant depots in LEO, LLO and LPO. An industry-operated, privately financed venture, with NASA as its initial customer, might provide a possible blueprint for future development and operation

- With industry interested in developing cislunar space and commerce, and competitive forces at work, the timeline for developing this capability could well be accelerated, quicker than any of us can imagine, and just the beginning of things to come....

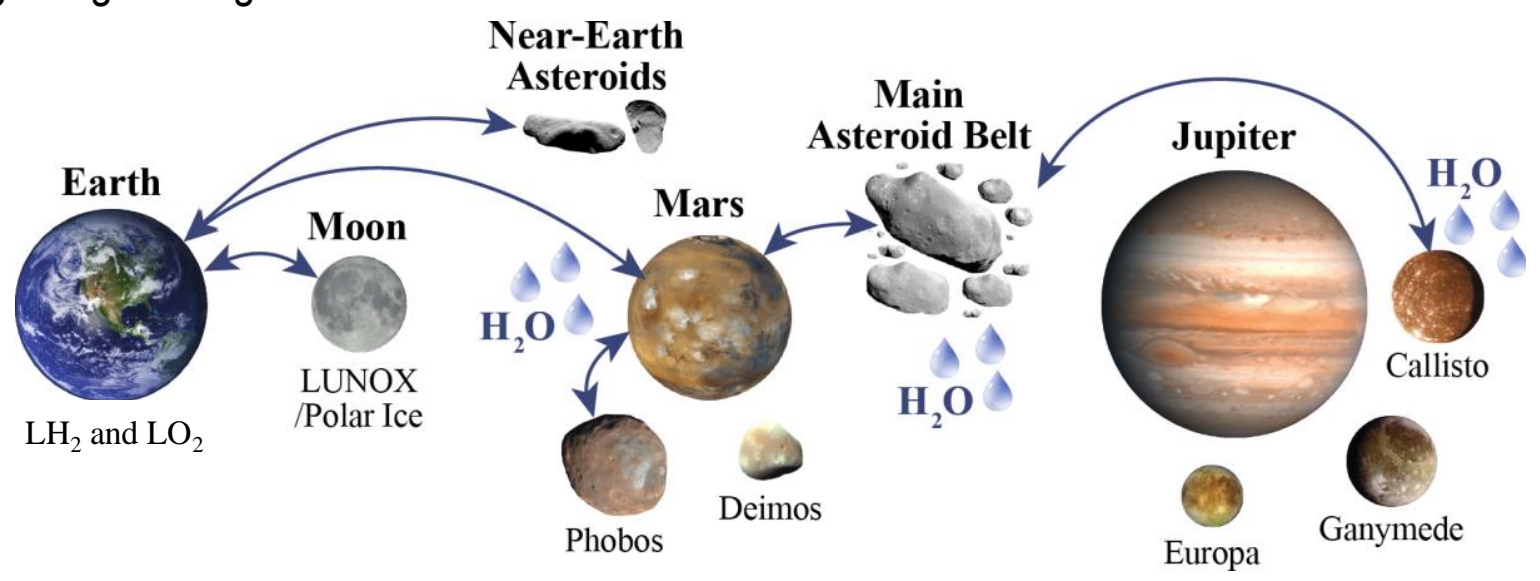

Human Expansion Possibilities using LANTR Propulsion and Extraterrestrial Propellant Resources 